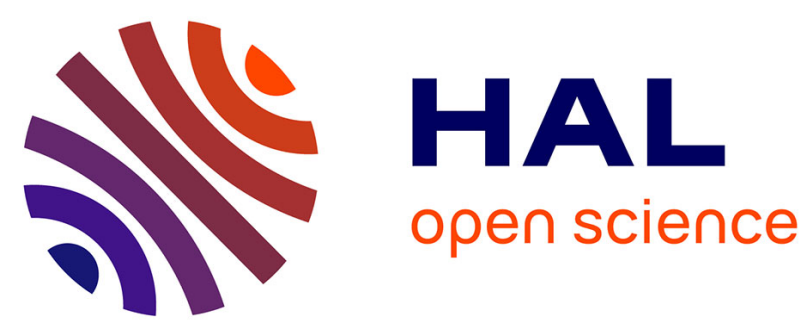

\title{
Effect of a $15 \%$ Increase in Preferred Pedal Rate on Time to Exhaustion During Heavy Exercise
}

Xavier Nesi, Laurent Bosquet, Serge Berthoin, Jeanne Dekerle, Patrick Pelayo

\section{To cite this version:}

Xavier Nesi, Laurent Bosquet, Serge Berthoin, Jeanne Dekerle, Patrick Pelayo. Effect of a $15 \%$ Increase in Preferred Pedal Rate on Time to Exhaustion During Heavy Exercise. Canadian Journal of Applied Physiology, 2004, Canadian journal of applied physiology = Revue canadienne de physiologie appliquee, 29, pp.146-56. hal-02400470

\section{HAL Id: hal-02400470 \\ https://hal.univ-lille.fr/hal-02400470}

Submitted on 24 Nov 2020

HAL is a multi-disciplinary open access archive for the deposit and dissemination of scientific research documents, whether they are published or not. The documents may come from teaching and research institutions in France or abroad, or from public or private research centers.
L'archive ouverte pluridisciplinaire HAL, est destinée au dépôt et à la diffusion de documents scientifiques de niveau recherche, publiés ou non, émanant des établissements d'enseignement et de recherche français ou étrangers, des laboratoires publics ou privés. 
1 Scope of the journal: Training and testing

2 Title: Effects of a $15 \%$ increase of spontaneously chosen pedal rate on oxygen 3 consumption kinetics during heavy exercise.

4 Running title: Increase of spontaneously chosen pedal rate

5 Authors : X. NESI ${ }^{1}$, L. BOSQUET ${ }^{1}$, S. BERTHOIN ${ }^{1}$, F. MATON ${ }^{2}$, P. PELAYO $^{1}$

6 ' ${ }^{1}$ Laboratoire D’Études de la Motricité Humaine, FACUlté Des ScienCES DU SpORT ET

7 DE L'ÉdUCATION PHYSIQUe - UniVERSitÉ DE LILLE 2, FRANCE.

8 2Institut Régional de Biologie et de Médecine du Sport De Lille, Faculté des 9 SCIEnCES DU Sport ET DE L’ÉduCATION PhysiQue, France.

10 Address for correspondence: Patrick Pelayo, Faculté des Sciences du Sport et de 11 l'Éducation Physique, 9 rue de l'université, 59790 Ronchin, France. e-mail: pelayo@hp-sc.univ-lille2.fr Phone: 0033320887379

$14 \quad$ Fax: 0033320887377

15 


\section{Abstract}

The purpose of this study was to assess the fast and slow $\dot{\mathrm{V}} \mathrm{O}_{2}$ component and exhaustion time during a heavy constant-power test (CPT) under two different pedal conditions. The oxygen consumption kinetics was analysed through mathematical modelling of the breath-by-breath gas exchange response to heavy cycling exercise. After continuous graded test, seven welltrained cyclists performed two all-out CPT. The first CPT was cycled at spontaneously chosen pedal rate (SCPR) and the second one at $+15 \%$ SCPR. As expected, the present study reported a significant decrease of exhaustion time on CPT at $+15 \%$ SCPR (respectively, $465.1 \pm 138.6$ vs $303.0 \pm 42.5 \mathrm{~s} ; \mathrm{P}<0.05)$ without change in $\dot{V} O_{2}$ kinetics between the two pedal rate conditions. Moreover, the decrease of exhaustion time was inverse correlated with variation of aerobic demand computed between the two pedal rate conditions. In conclusion, it could be suggested that factors implicated in this decrease of exercise tolerance were principally neural and muscular factors. Nevertheless, the capacity to maintain the aerobic demand regardless of the increase of pedal rate could be assumed like factor associated to the performance in road race.

Key words: Cadence; Cycling; Endurance time; Mathematical modelling. 


\section{Introduction}

In cycling, a great diversity in the choice of spontaneously chosen pedal rate (SCPR) has been reported according to the population studied. Experienced cyclists routinely use high pedal rate from 90 to $100 \mathrm{rpm}$ in laboratory tests or competitive events while inexperienced subjects use usually 50 to $60 \mathrm{rpm}$ [14]. The variations of preferred cadence could be related to training status and pedal skill $[15,23]$. In road race conditions, cyclists have the use of limited gear ratio and must adopt pedal rate greater than $100 \mathrm{rpm}$ in order to ride over $55 \mathrm{~km} \cdot \mathrm{h}^{-1}$. Thus, during specific sessions of training, cyclists often increase consciously their spontaneously pedal rate to become more comfortable and efficient while pedalling at cadence close to 110 $\mathrm{rpm}$. Some studies have analysed the effect of cadence on the power-time relationship in cycling (McNaughton and Thomas, 1996; Hill et al., 1995; Carnevale and Gaesser, 1991). McNaughton and Thomas (1996) and Carnevale and Gaesser (1991) have shown that cycling at low pedal rate $(50-60 \mathrm{rpm})$ make it possible to inexperienced cyclists to achieve better performance in heavy constant-power tests. These previous studies concluded that increasing pedal rate leads a to decrease exercise tolerance and exhaustion time. Nevertheless, on the best of our knowledges, this point have never been verify in trained and experienced cyclists. During the transition from rest or unloaded cycling to constant-load exercise of moderate intensity (below the anaerobic threshold), after the cardio-dynamic phase (phase 1), $\dot{V} \mathrm{O}_{2}$ rises in an approximately mono-exponential fashion (phase 2) to attain a new steady state (phase 3) within 3-5-min in normal subjects. In contrast, $\dot{V} O_{2}$ response to constant-load exercise of heavy intensity (superior to anaerobic threshold) is complicated by the development of an additional component of $\dot{V} O_{2}$ such that attainment of a new steady state, if attained, is delayed [31]. Barstow et al. [2] have studied the effect of different imposed frequency $(45,60$, 75 and $90 \mathrm{rpm}$ ) on the $\dot{V} O_{2}$ kinetics in heavy exercise and have concluded that pedal frequency has no significant effect in inexperienced subjects. Nevertheless, they did not allow 
the subjects to choose their own pedal rate as they normally do everyday during training and competition. Likewise, Marsh and Martin $(1993 ; 1997)$ have studied the aerobic demand response to cadence manipulation and reported a curvilinear relationship with higher cadence producing higher oxygen consumption. Up to this date, only the study of Billat et al. (1999) has analysed the effect of decrease in spontaneously chosen cadence of exercise on $\dot{V} O_{2}$ slow component. They have reported no difference on $\dot{V} \mathrm{O}_{2}$ slow component between the two cadences (freely $v s$ lower of $10 \%$ ). A limitation of this study was the characterization of the slow component, which involved the simple calculation of the difference between $\dot{V} O_{2}$ at 3-min and $\dot{V} \mathrm{O}_{2}$ at the end of exercise. Indeed, the use of the model validated by Barstow and Molé [3] makes it possible to determine more accurately the components of the $\dot{V} O_{2}$ kinetics [5]. Moreover, Billat et al. (1999) have reported an amplitude of slow component significantly higher during cycling than in running with no difference in exhaustion time, suggesting that the relationship between the $\dot{V} O_{2}$ slow component and the fatigue process remains unclear. Nevertheless, Demarle et al. (2001) have shown that the decrease of oxygen deficit observed after a specific program of endurance training reflects a faster adjustment on $\dot{V} O_{2}$ kinetics (i.e. decreasing of $\tau_{1}$ ) and was correlated with the improvement of exhaustion time. Based on this background, it seems necessary to verify whether the decrease of endurance time during heavy exercise is linked to adjustment and/or magnitude of $\dot{V} \mathrm{O}_{2}$ response.

Thus, the purpose of this study was to assess the fast and slow component of $\dot{V} O_{2}$, using the mathematical modelling procedure [3], and the performance during a heavy constant-power test (CPT) in well-trained cyclists when the pedal rate was spontaneously chosen or set at + $15 \%$ SCPR. It was hypothesised, on the one hand that an increase of $+15 \%$ SCPR induce a decrease of performance with no significant change in $\dot{V} \mathrm{O}_{2}$ kinetics and on the other hand, 
that the decrease of endurance time is correlated with an increase of the time constant of primary $\dot{V} \mathrm{O}_{2}$ component and amplitude $\dot{V} \mathrm{O}_{2}$ response .

\section{Methods}

\section{Subjects}

Seven competitive cyclists (mean $\pm \mathrm{SD}$ : age $27.4 \pm 4.2 \mathrm{yr}$; height $1.77 \pm 0.03 \mathrm{~m}$; body mass $72.3 \pm 3.6 \mathrm{~kg}$; weekly hourly volume of training $12.1 \pm 2.6 \mathrm{~h} . \mathrm{wk}^{-1}$ ) volunteered to take part in this study, which was approved by the French National Committee for Clinical Research. All subjects gave informed written consent to participate in this study and underwent a complete medical examination prior to the experiments. All measurements were carried out under medical supervision in a climate-controlled laboratory $\left(21\right.$ to $\left.22^{\circ} \mathrm{C}\right)$.

\section{Testing procedure}

All the subjects were familiar with all procedures and performed:

- a maximal graded test (Tmax) where the power output was set at $100 \mathrm{~W}$ and increased by $25 \mathrm{~W}$ every minute, in order to measure the maximal oxygen uptake ( $\dot{V} \mathrm{O}_{2}$ max), to determine the maximal aerobic power (MAP), and the ventilatory thresholds $\left(\mathrm{VT}_{1}\right.$ and $\left.\mathrm{VT}_{2}\right)$

- two constant power tests (CPT) set at a power output that theoretically requires $50 \%$ of the difference in $\dot{V} O_{2}$ between $\mathrm{VT}_{2}$ and $\dot{V} O_{2} \max (\mathrm{p} \Delta 50)$. The first CPT was performed at SCPR, while the second one was performed at $+15 \%$ of SCPR of the preceding session.

Each session took place on non-consecutive days at the same time $( \pm 1 \mathrm{~h})$ in order to minimise possible effects of diurnal biological variations on the results. Subjects were instructed to arrive at the laboratory in a fully hydrated state and to avoid strenuous exercise in the 48-h preceding a test session. Subjects were required to cycle on their own bicycles, which were attached to a Spintrainer ergometer (Technogym, Gambettola, Italy). This device simulates a real life time-trial situation since the subjects can choose the gear ratio and pedal rate depending on the power output required. The ergometer was calibrated for each subject 
immediately before each test. Calibration of the Spintrainer ergometer consists of a "rundown" test. The cyclist is required to cycle up to a speed of $34 \mathrm{~km} \cdot \mathrm{h}^{-1}$ and then to stop pedalling immediately the Spintrainer display shows the message "STOP." The cyclist must then remain motionless on his cycle while the calibration takes place. The speed-decay curve is drawn from $34 \mathrm{~km} \cdot \mathrm{h}^{-1}$ to $5 \mathrm{~km} \cdot \mathrm{h}^{-1}$. The ergometer's built-in computer generates a reference decay curve specific to the subject's body mass that is entered before the calibration test. If the acquired decay curve closely fits the reference decay curve, the calibration is accepted. If not, the rolling resistance is adjusted automatically by adjusting the electromagnetic resistance system, and a second calibration test is performed. The test is repeated with adjustments to rolling resistance until the Spintrainer display accepts the calibration as correct. This usually takes two to three attempts.

\section{Determination of $\dot{V} \mathrm{O}_{2}$ max, MAP and VT}

The maximal graded test was preceded by a 3-min warm-up period at $100 \mathrm{~W}$. This initial work rate was then increased by $25 \mathrm{~W} \cdot \mathrm{min}^{-1}$. To ensure that $\dot{V} O_{2}$ max was reached, subjects were encouraged to continue as long as possible so that a levelling off in the $\dot{V} O_{2}$ course occurred. The test ended at the point of voluntary exhaustion. During the test, the subjects breathed through a facemask. Measurement of oxygen uptake $\left(\dot{V} \mathrm{O}_{2}\right)$, carbon dioxide output $\left(\dot{V} C O_{2}\right)$, minute ventilation $\left(\dot{V}_{E}\right)$ and respiratory frequency (f) were carried out throughout each test using a breath-by-breath portable gas analyser (Cosmed $\mathrm{K} 4 \mathrm{~b}^{2}$, Roma, Italy). It has been shown to be a valid instrument for the measurement of $\dot{V} O_{2}$ (McLaughlin et al., 2000). The Cosmed $\mathrm{K}_{4} \mathrm{~b}^{2}$ oxygen analyser and carbon dioxide analyser were calibrated immediately before each testing session in accordance with manufacturer's guidelines. The calibration of the turbine flow-meter of the $\mathrm{K} 4 \mathrm{~b}^{2}$ was performed with a 3-L syringe (Quinton Instruments, Seattle, Washington). A 10-lead ECG (Quinton Instruments, Q-710, Seattle, Washington) was 
recorded continuously during tests to determine heart rate (HR). The mean respiratory exchange ratio (RER), and ventilatory equivalents in $\mathrm{O}_{2}\left(\dot{V}_{E} / \dot{V} O_{2}\right)$ and $\mathrm{CO}_{2}\left(\dot{V}_{E} / \dot{V} C O_{2}\right)$ values were calculated from the recorded measurements. The maximal values of $\dot{V} O_{2}, \mathrm{HR}$, $\dot{V} C O_{2}$, RER and $\dot{V}_{E}$ attained during the test were reported $\left(\dot{V} O_{2}\right.$ max, HRmax, $\dot{V} C O_{2}$ max, RERmax, $\dot{V}_{E} \max$ ). When no plateau of $\dot{V} O_{2}$ was achieved, maximal aerobic power (MAP) was identified as the peak power output, i.e. the maximal exercise intensity maintained during the last stage. When a plateau of $\mathrm{VO}_{2}$ was achieved, MAP was defined as the minimal exercise intensity, which can elicit $\dot{V} O_{2}$ max. A plateau of $\dot{V} O_{2}$ in the $\dot{V} O_{2}$-exercise intensity relationship was defined as an increase in oxygen uptake of less than $1.5 \mathrm{ml} \cdot \mathrm{min}^{-1} \cdot \mathrm{kg}^{-1}$ with the increase in exercise intensity. The single indices used individually in order to determine $\mathrm{VT}_{1}$ and $\mathrm{VT}_{2}$ for each subjects were $\mathrm{VE}, \mathrm{VCO}_{2}, \mathrm{VE} / \dot{V} O_{2}$ and $\mathrm{VE} / \mathrm{VCO}_{2}$. The following criteria were employed in selecting the thresholds: According to Wasserman et al. (1973), $\mathrm{VT}_{1}$ was defined as the minimal load at which $\mathrm{VE} / \dot{V} O_{2}$ exhibited a systematic increase without a concomitant increase in $\mathrm{VE} / \mathrm{VCO}_{2} . \mathrm{VT}_{2}$ corresponded to the minimal work rate at which the increase in $\mathrm{VE} / \dot{V} O_{2}$ went with an increase of $\mathrm{VE} / \mathrm{VCO}_{2}$ (Wasserman and McIlroy, 1964). Beaver et al. (1986) defined $\mathrm{VT}_{1}$ and $\mathrm{VT}_{2}$ as the work rates associated with a first and a second non-linear increase of $\mathrm{VE}$ and $\mathrm{VCO}_{2}$. According to the criteria outlined above, three independent investigators blindly reviewed the plots of each index and made individual determinations of $\mathrm{VT}_{1}$ and $\mathrm{VT}_{2}$. Extrapolation of the relationship between $\dot{V} O_{2}$ and power output for exercise at sub-VT2 intensities was used to estimate the power output at $\Delta 50$ $(\mathrm{p} \Delta 50)$.

Measurements of blood lactate concentrations ([La]) were obtained from capillary blood samples. The fingertip was cleaned with an alcohol swab, dried and then punctured with an automated lancet to sample blood into capillary tubes to determine [La] three minute post- 
exercise. Blood samples were analysed using Dr Lange's ${ }^{\circledR}$ photometric method (Berlin, Germany).

Determination of SCPR, exhaustion time and $\dot{V} \mathrm{O}_{2}$ kinetics

During a initial exercise of 3-min, each subject self-selected the pedal rate (SCPR) and gear ratio allowing to develop $\mathrm{p} \Delta 50$. Marsh et Martin (1997) reported that some day-to-day variation in SCPR exists but that in general this measure in quite stable. Thus, in order to keep power output constant during each $\mathrm{CPT}$, the cyclist cycled with cadence feedback and was encouraged to maintain the pedal rate spontaneously chosen in initial exercise $( \pm 1 \mathrm{rpm})$ without change of gear ratio. The CPT began with a 6-min warm-up performed at a power output corresponding to $\mathrm{VT}_{1}$ and the transition from the warm-up to exercise was complete within 15-s. Subjects were instructed to cycle for as long as possible and exhaustion was defined as the point at which the subject could no maintain the correct pedal rate (SCPR or + $15 \%$ SCPR). No indication was given as to the time elapsed and the exhaustion time was recorded to the nearest second for each subject.

The end-values of $\dot{V} O_{2}$, HR and $\dot{V}_{E}$ attained during each CPT were reported and termed respectively end- $\dot{V} O_{2}$, end-HR and end- $\dot{V}_{E}$. End-HR and end- $\dot{V}_{E}$ were computed from the average value of recorded measurements during the last 30-s of CPT. End- $\dot{V} \mathrm{O}_{2}$ was calculated from the equation 1. The time course of alveolar $\dot{V} \mathrm{O}_{2}$ after the onset of exercise was described in terms of an exponential function that was fit to the data with the use of nonlinear regression techniques in which minimizing the sum of the mean squares of the difference between the fitted $\dot{V} O_{2}$ and the experimental data (Solver from Excel 9.0 Microsoft Corporation). The mathematical model of the breath-by-breath $\dot{V} O_{2}$ response consisted of three exponentials terms, each representing one phase of the response [3]. The first 
exponential term started with the onset of exercise $($ time $=0)$, whereas the other terms began after independent time delays

$$
\begin{gathered}
\dot{V} O_{2}(\mathrm{t})=\dot{V} O_{2}(\mathrm{w})+\mathrm{A} 0 \times\left(1-\mathrm{e}^{-\mathrm{t} / \tau_{0}}\right) \\
\text { Phase } 1 \text { (initial component) } \\
+\mathrm{A} 1 \times\left(1-\mathrm{e}^{\left.-\left(\mathrm{t}-\mathrm{TD}_{1}\right) / \tau_{1}\right)}\right. \\
\text { Phase } 2 \text { (primary component) } \\
+\mathrm{A} 2 \times\left(1-\mathrm{e}^{-\left(\mathrm{t}-\mathrm{TD}_{2}\right) / \tau_{2}}\right) \\
\text { Phase } 3 \text { (slow component) }
\end{gathered}
$$

where $\dot{V} O_{2}(w)$ is the average value over the last minute of warm-up at $\mathrm{VT}_{1} ; \mathrm{A}_{0}, \mathrm{~A}_{1}, \mathrm{~A}_{2}$ are the asymptotic amplitudes for the exponential terms; $\tau_{0}, \tau_{1}, \tau_{2}$ are the time constants; $\mathrm{TD}_{1}$, $\mathrm{TD}_{2}$ are the time delays. The phase 1 term was terminated at the start of phase 2 (i.e., at $\mathrm{TD}_{1}$ ) and assigned the value for that time $\left(\mathrm{A}_{0}{ }^{\prime}\right)$

$$
\mathrm{A}_{0}{ }^{\prime}=\mathrm{A}_{0} \times\left(1-\mathrm{e}^{-\mathrm{TD}_{1} / \tau_{0}}\right)
$$

The amplitude of phase $1\left(\mathrm{~A}_{0}{ }^{\prime}\right)$ and the amplitude of phase $2\left(\mathrm{~A}_{1}\right)$ were added to calculate the amplitude at the end of the primary component $\left(\mathrm{A}_{1}{ }^{\prime}\right)$. The slow component at the end of exercise $\left(\mathrm{A}_{2}{ }^{\prime}\right)$ was calculated and was used in preference to the asymptotic value [2]. The increase in $\dot{V} O_{2}$ above $\dot{V} O_{2}$ (w) at the end of exercise was calculated as the sum of $\mathrm{A}_{1}$ ' and $\mathrm{A}_{2}$ ' and termed $\mathrm{EE} \dot{V} \mathrm{O}_{2}$. The end-value of $\dot{V} \mathrm{O}_{2}$ (i.e. end- $\dot{V} \mathrm{O}_{2}$ ) was equal to the sum of $\dot{V} O_{2}(\mathrm{w})$ and $\mathrm{EE} \dot{V} \mathrm{O}_{2}$.

\section{Statistical analysis}

Standard statistical methods were used for the calculation of means and standard deviations. Normal Gaussian distribution and homogeneity of variance were verified by the Shapiro-Wilk and the Levenne tests, respectively. Paired t-test, and where appropriate, Wilcoxon matched pairs test were used to compare the differences between the two pedal rate conditions. Relationship between variations of exhaustion time and $\dot{V} \mathrm{O}_{2}$ kinetics parameters were evaluating using a Pearson correlation coefficient. A two-way analysis of variance with 
repeated measures was used to test the overall effect of time and pedal rate on the $\dot{V}_{E}$ and HR values averaged each 30-s. Compound symmetry, or sphericity, was verified by the Mauchley test [27]. When the assumption of sphericity was not met, the significance of F-ratios was adjusted according to the Greenhouse-Geisser procedure [26]. Statistical significance was set at $\mathrm{P}=0.05$ level for all analysis. All calculations were made with Statistica (Release 5.5, Statsoft, Tulsa, USA).

\section{Results}

\section{Graded test.}

Mean MAP value was $353.6 \pm 52.9 \mathrm{~W}$ and mean $\dot{V} O_{2}$ max value was $4419.0 \pm 692.6 \mathrm{ml} . \mathrm{min}^{-}$ ${ }^{1}$; corresponding to $61.2 \pm 9.2 \mathrm{ml} \cdot \mathrm{min}^{-1} \cdot \mathrm{kg}^{-1}$. The $\mathrm{VT}_{1}$ and $\mathrm{VT}_{2}$ represented respectively $52.7 \pm$ 6.3 and $86.0 \pm 4.7 \% \dot{V} O_{2}$ max. Mean $\mathrm{HRmax}, \dot{V} \mathrm{CO}_{2} \max , \dot{V}_{E} \max$ and RERmax values were $186.3 \pm 9.8$ beats. $\mathrm{min}^{-1}, 4785.9 \pm 752.1 \mathrm{ml} \cdot \mathrm{min}^{-1}, 189.9 \pm 20.41 . \mathrm{min}^{-1}$ and $1.18 \pm 0.03$, respectively. Mean blood lactate concentration value was $13.7 \pm 3.4$ mmol..$^{-1}$ and mean HRmax achieved $96.8 \pm 4,8 \%$ of theoretical maximal HR.

\section{Constant-power tests.}

During constant-power tests (CPT) set at $\mathrm{p} \Delta 50$ (equal to $328.0 \pm 45.1 \mathrm{~W}$ ), the average value of SCPR was $94.3 \pm 3.8 \mathrm{rpm}$. Exhaustion time recorded at SCPR was significantly longer than at $+15 \% \operatorname{SCPR}(465.1 \pm 138.6$ vs $303.0 \pm 42.5 \mathrm{~s}$, respectively; $\mathrm{P}<0.05)$.

Despite the difference between the exercise modes in terms of pedal rate (SCPR and $+15 \%$ SCPR), no significant difference $(\mathrm{P}>0.05)$ was found in end- $\dot{V} O_{2}(3911.9 \pm 552.6 v s 4125.5$ $\pm 702.8 \mathrm{ml} . \mathrm{min}^{-1}$, respectively), end-HR (175.3 \pm 3.7 vs $179.8 \pm 4.8$ beat.min ${ }^{-1}$, respectively) and blood lactate concentration (12.9 $\pm 5.2 v s 13.2 \pm 3.6 \mathrm{mmol.}^{-1}$, respectively), except for $\dot{V}_{E}$ where the mean end-value of CPT at $+15 \%$ SCPR was significantly higher $(136.1 \pm 13.9$ vs $\left.165.3 \pm 25.61 . \mathrm{min}^{-1} ; \mathrm{P}<0.01\right)$. 
No difference of $\dot{V} \mathrm{O}_{2}$ kinetics parameters and HR response were noticed between each pedal rate conditions $\left(\mathrm{P}>0.05\right.$; Table I). The $\dot{V} O_{2}$ response of a typical cyclist performing under the two different pedal rate conditions is shown in Figure 1. A significant overall effect of time and pedal rate was found on the $\dot{V}_{E}$ response $(\mathrm{P}<0.05)$; the "drift" $\dot{V}_{E}$ was significantly larger during CPT cycled at $+15 \%$ SCPR.

No relationship was reported between the variation of time constant of the primary $\dot{V} O_{2}$ component (i.e. $\left.\tau_{1}\right)$ and the decrease of exhaustion time in CPT at $+15 \% \operatorname{SCPR}(r=0.17$; P > $0.05)$. Finally, the decrease of exhaustion time $(-31.1 \pm 15.7 \%)$ was significantly related to changes of $\mathrm{A}_{1}{ }^{\prime}(17.0 \pm 29.6 \% ; \mathrm{r}=-0.87 ; \mathrm{P}<0.02)$ and end $-\dot{V} O_{2}(16.7 \pm 21.4 \% ; \mathrm{r}=-0.87 ; \mathrm{P}<$ 0.02) computed during the CPT set at $+15 \%$ SCPR (Figure 2).

\section{Discussion}

The aim of this study was to assess the endurance time and parameters of oxygen consumption kinetics during heavy constant-power test under two different pedal rate conditions (spontaneously chosen pedal rate: SCPR $v s+15 \%$ SCPR). As hypothesised, the endurance time decreased in CPT cycled at $+15 \%$ SCPR with no change both on $\dot{V} O_{2}$ fast and slow components. No relationship was reported between the variation of time constant of the primary $\dot{V} \mathrm{O}_{2}$ component (i.e. $\tau_{1}$ ) and the decrease of exhaustion time in CPT at $+15 \%$ SCPR that was inconsistence with hypothesis. However, the decrease of performance in CPT at $+15 \%$ SCPR was related to changes of amplitude of fast $\dot{V} O_{2}$ component and global $\dot{V} O_{2}$ response.

To make a valid description of $\dot{V} O_{2}$ kinetics during heavy exercise for all subjects, a normalization of the exercise intensity with reference to both $\mathrm{VT}_{2}$ and $\dot{V} O_{2}$ max was chosen (i.e., we used the " $\Delta$ " concept; [29]). This approach seems to be preferable to normalize the exercise intensity by $\dot{\mathrm{V}} \mathrm{O}_{2}$ max alone, because the latter can lead to differences in metabolic 
and perceptual stress, depending on the proximity of the exercise intensity to the $\mathrm{VT}_{2}$ [16]. The mean $\dot{V} \mathrm{O}_{2}$ max estimated during the graded test was in accordance with the values determined in subjects who are specifically trained in cycling $[6,8,9]$. Nevertheless, the anaerobic threshold solved by ventilatory analysis (i.e. $\mathrm{VT}_{2}$ ) occurred at a higher percentage of $\dot{V} \mathrm{O}_{2}$ max. Thus, the power output at $\Delta 50$ represented a higher fraction of maximal aerobic power (MAP) than previously computed in cyclists $[8]$ or in untrained subjects $[2,10]$. In the present study, cyclists were able to maintain $\mathrm{p} \Delta 50$ (corresponding to $93.2 \pm 3.7 \% \mathrm{MAP}$ ) during $7 \mathrm{~min} 45 \mathrm{~s} \pm 2 \min 19 \mathrm{~s}$ at SCPR. In triathletes, Billat et al. [8,9] reported exhaustion time equating to $10 \min 37 \mathrm{~s} \pm 4 \min 11 \mathrm{~s}$ and $13 \min 32 \mathrm{~s} \pm 4 \min 52 \mathrm{~s}$ during exercise cycled respectively at $90 \% \mathrm{MAP}$ and $\mathrm{p} \Delta 50$ (corresponding to $86.3 \pm 1.9 \% \mathrm{MAP}$ ). Thus, considering the hyperbolic relationship between relative power output and exhaustion time [21], the present results are in agreement with these previous studies. Many authors (Takaishi et al.,1998; Ericson et al., 1986) have shown that cycling training have a significant effect on the pedal skill and legcoordination. Hence, experienced cyclists have been chosen in this study in order to limited the probable effect of pedal skill on the exercise tolerance in supraSCPR condition. Moreover, Takaishi et al. (1998) suggested that pedalling skills influence the preferred cadence selection up to high pedal rate (80-90 rpm). Supported by the assumptions of Takaishi et al. (1998), the average SCPR value reported in the present study $(94.1 \pm 4.1$ rpm) confirmed the subject's cycling experience.

Many authors (McNaughton and Thomas, 1996; Hill et al., 1995; Carnevale and Gaesser, 1991) have shown in inexperienced cyclists that high pedal rates $(90,100$ and $110 \mathrm{rpm})$ compromise endurance performance compared to lower pedal rates $(50$ and $60 \mathrm{rpm})$. In the present study, the increase of $15 \%$ of SCPR $(94.1 \pm 4.1$ vs $108.3 \pm 4.7 \mathrm{rpm})$ induced a significant decrease in exhaustion time of cycling exercise performed at $\mathrm{p} \Delta 50(31.1 \pm 15.7 \%)$. McNaughton and Thomas [20] reported no significant difference on power asymptote of the 
hyperbolic power-duration relationship between the two high pedal rate conditions (90 and $110 \mathrm{rpm}$ ) that is not in accordance with the present results. Nevertheless, pedal rate values of $90 \mathrm{rpm}$ or $110 \mathrm{rpm}$ could influence similarly the power-duration relationship parameters in inexperienced cyclists who adopt generally low SCPR values. Hill et al. (1995) reported no significant difference on the parameters of power-duration relationship between the lower pedal rate $(60 \mathrm{rpm})$ and preferred pedal rate (from 83 to $89 \mathrm{rpm}$ ) in recreational active subjects. Similarly, Billat et al. [8] reported no significant difference on exhaustion time during tests cycled at SCPR and $-10 \% \operatorname{SCPR}(82.5 \pm 10.0$ vs $73.4 \pm 8.9 \mathrm{rpm})$ in triathletes. From all these data, we can concluded that pedal rate at SCPR or slightly slower make it possible to optimise the endurance time and that an increase of pedal rate over SCPR leads to a decrease of cycling exercise tolerance.

The majority of time-based parameters of the $\dot{V} \mathrm{O}_{2}$ kinetics fitted from the regression is in accordance with those computed in active or trained subjects during heavy exercise (Carter et al., 2000; Barstow et al., 1996; 1993). However, it was surprising to notice that the adjustment of primary component was slow (i.e. high $\tau_{1}$ value) in this group of trained cyclists. Indeed, some studies have shown a faster $\dot{V} O_{2}$ on-kinetic adjustment in individuals with higher $\dot{V} \mathrm{O}_{2}$ max values and after endurance training program (Chilibeck et al. [11] and Phillips et al. [22]). In the present study, there was no recovery between warm-up cycled at $\mathrm{VT}_{1}$ and exercise performed at $\mathrm{p} \Delta 50$ increasing the $\dot{V} \mathrm{O}_{2}$ value at the onset of CPT $\left(2300 \mathrm{ml} \cdot \mathrm{min}^{-1}\right)$. In previous studies (Carter et al., 2000; Barstow et al., 1996; 1993), the constant-load exercise take place after a period of rest or unloaded cycling and the $\dot{V} \mathrm{O}_{2}$ baseline was in a range from 400 to $1000 \mathrm{ml} \cdot \mathrm{min}^{-1}$. Thus, it could be put forward that a lower difference between $\dot{V} O_{2}$ baseline and primary $\dot{V} O_{2}$ steady state could induce a slow down of $\dot{V} O_{2}$ adjustment in the early minutes of heavy exercise. 
As hypothesised, no significant difference was observed in amplitudes (i.e.; in $\mathrm{A}_{0}{ }^{\prime}, \mathrm{A}_{1}$ ', and $\left.\mathrm{A}_{2}{ }^{\prime}\right)$ or in time-based parameters (i.e., $\mathrm{TD}_{1}, \mathrm{TD}_{2}, \tau_{0}, \tau_{1}, \tau_{2}$ ) between the two pedal rate conditions. In a previous study, Barstow et al. [2] have shown that changing pedal rate, from 45 to $90 \mathrm{rpm}$, does not alter the overall characteristics of $\dot{V} \mathrm{O}_{2}$ kinetic. Moreover, Billat et al. [8] have shown that decrease of $10 \%$ SCPR have no influence on the difference in $\dot{V} O_{2}$ between 3 and 6-min of heavy exercise. From the present results and those of previous studies, it was reasonable to conclude that a variation of $\pm 15 \%$ of SCPR in experienced cyclists has any significant effect on the $\dot{V} \mathrm{O}_{2}$ kinetics.

No significant difference was reported in end-values of $\dot{V} O_{2}$, HR and blood lactate concentration, except for end- $\dot{V}_{E}$ that is in accordance with the results of Chavarren and Calbet (1999). The larger "drift" of $\dot{V}_{E}$ during supra-SCPR conditions can be related to the mechanism of respiratory control from muscular input (Duranti et al., 1991). Indeed, an increase of pedal rate corresponds to an increase in the muscle activation-relaxation rate and in the muscle shortening velocity. Takaishi et al. $(1996 ; 1994)$ have shown that SCPR was closely related to the pedal rate minimizing the neuromuscular fatigue in working muscles and Beelen and Sargeant (1993) have found a 14\% greater reduction in maximal peak power after a prior 6-min exercise at $120 \mathrm{rpm}$ compared to $60 \mathrm{rpm}$. Thus, an increase of SCPR decreasing the exercise tolerance could be linked to neural and muscular factors such as a relatively greater contribution of fatigue-sensitive fibres, an increase of firing rate and/or progressive recruitement of additional motor units . Moreover, no relationship was reported between the variation of time constant of the primary $\dot{V} O_{2}$ component (i.e. $\tau_{1}$ ) and the decrease of exhaustion time in CPT at $+15 \%$ SCPR that was inconsistence with hypothesis. From this result, it seems reasonable to suggest that the difference of exercise tolerance was not in 
relation to the oxygen delivery to the active muscles in the first minutes of CPT which highligths the unclear relation between the $\dot{V} O_{2}$ kinetics and the fatigue process.

Nevertheless, the decrease of exhaustion time was correlated with variations of amplitude both of fast $\dot{V} O_{2}$ component and global $\dot{V} O_{2}$ response. Higher the increase of amplitude of the primary $\dot{V} \mathrm{O}_{2}$ component and global $\dot{V} \mathrm{O}_{2}$ response, higher the decrease of exhaustion time in CPT at $+15 \%$ SCPR. These changes of $\dot{V} O_{2}$ amplitude between the two pedal rate conditions could explain the inter-individual variations in the decrease of exhaustion time (from 15 to $60 \%$ ). According to previous study (Goldnick et al., 1974; Vollestad and Blom, 1985), the work intensity in the present study corresponds to an intensity exercise at which fast twitch (FT) fibres are recruited in addition to the slow twitch (ST) fibres. This fibre type is known to be less efficient energetically that ST fibres (Wills and Jackman, 1994). Moreover, Sargeant (1994) suggested that FT fibres may be recruited preferentially for the same external power output when contraction velocity is high. Thus, it could be speculated that cyclists who recruit a greater FT fibres in the early minutes of CPT at $+15 \% \mathrm{SCPR}$ present a greater amplitude of the fast $\dot{V} O_{2}$ component and $\dot{V} O_{2}$ response leading to a decrease of exercise tolerance.

Conclusion

The SCPR makes it possible cyclists to continue for longer at heavy exercise, in comparison to a $15 \%$ increase of SCPR. This decrease of CPT performance observed at $+15 \%$ SCPR was not associated with change in $\dot{V} O_{2}$ kinetics and could be related to a greater activity of working muscles, neuromuscular fatigue and FT fibres recruitment. However, higher the increase of amplitude of the primary $\dot{V} O_{2}$ component and global $\dot{V} O_{2}$ response, higher the decrease of exhaustion time in CPT at $+15 \%$ SCPR. In practical terms, these results suggest that it is better for competitive cyclists to adopt pedal rate clote to these ones frequently used 
349 during training in order to optimise their road race performance, essentially during high 350 intensity phases. However, using limited crank gear, cyclists were obliged to adopt pedal rate 351 greater than $100 \mathrm{rpm}$ during phases where the speed was greater to $55 \mathrm{~km} \cdot \mathrm{h}^{-1}$ (back wind, 352 descent, finish of flat stage). Thus, the capacity to maintain the aerobic demand regardless of 353 the increase of pedal rate could be assumed like factor associated to the performance in road 354 race. 
357 Table I. Parameters of oxygen uptake response during CPT at $\mathrm{p} \Delta 50$ under different pedal rate 358 conditions: spontaneously chosen pedal rate (SCPR) and $+15 \%$ SCPR. Please refer to Eq. 1 and see the text for details. Rel. $\mathrm{A}_{2}{ }^{\prime}\left(\mathrm{A}_{2}{ }^{\prime} / \mathrm{EE} \dot{V} \mathrm{O}_{2}\right)$ relative contribution of the slow component to a net increase in $\dot{V} O_{2}$ at end exercise.

\begin{tabular}{|c|c|c|}
\hline Variable & SCPR & $+15 \%$ SCPR \\
\hline$\dot{V} O_{2}(\mathrm{w})\left(\mathrm{ml} \cdot \mathrm{min}^{-1}\right)$ & $2338.3 \pm 181.5$ & $2282.3 \pm 194.7$ \\
\hline $\mathrm{A}_{0},\left(\mathrm{ml} \cdot \mathrm{min}^{-1}\right)$ & $364.3 \pm 121.0$ & $405.1 \pm 171.6$ \\
\hline$\tau_{0}(\mathrm{~s})$ & $14.8 \pm 4.8$ & $21.2 \pm 8.9$ \\
\hline $\mathrm{TD}_{1}(\mathrm{~s})$ & $25.1 \pm 7.5$ & $18.3 \pm 8.5$ \\
\hline $\mathrm{A}_{1}{ }^{\prime}\left(\mathrm{ml} \cdot \mathrm{min}^{-1}\right)$ & $1227.8 \pm 303.5$ & $1458.4 \pm 426.1$ \\
\hline$\tau_{1}(\mathrm{~s})$ & $30.0 \pm 13.5$ & $44.6 \pm 16.3$ \\
\hline $\mathrm{TD}_{2}(\mathrm{~s})$ & $255.8 \pm 41.9$ & $232.7 \pm 26.4$ \\
\hline $\mathrm{A}_{2}{ }^{\prime}\left(\mathrm{ml} \cdot \mathrm{min}^{-1}\right)$ & $345.8 \pm 130.9$ & $384.8 \pm 204.4$ \\
\hline$\tau_{2}(\mathrm{~s})$ & $81.6 \pm 39.1$ & $83.5 \pm 41.8$ \\
\hline Rel. $\mathrm{A}_{2}^{\prime}\left(\% \mathrm{EE} \dot{V} \mathrm{O}_{2}\right)$ & $21.9 \pm 11.0$ & $20.1 \pm 11.9$ \\
\hline $\mathrm{EE} \dot{V} \mathrm{O}_{2}\left(\mathrm{ml} . \mathrm{min}^{-1}\right)$ & $1573.6 \pm 291.1$ & $1843.2 \pm 549.6$ \\
\hline
\end{tabular}




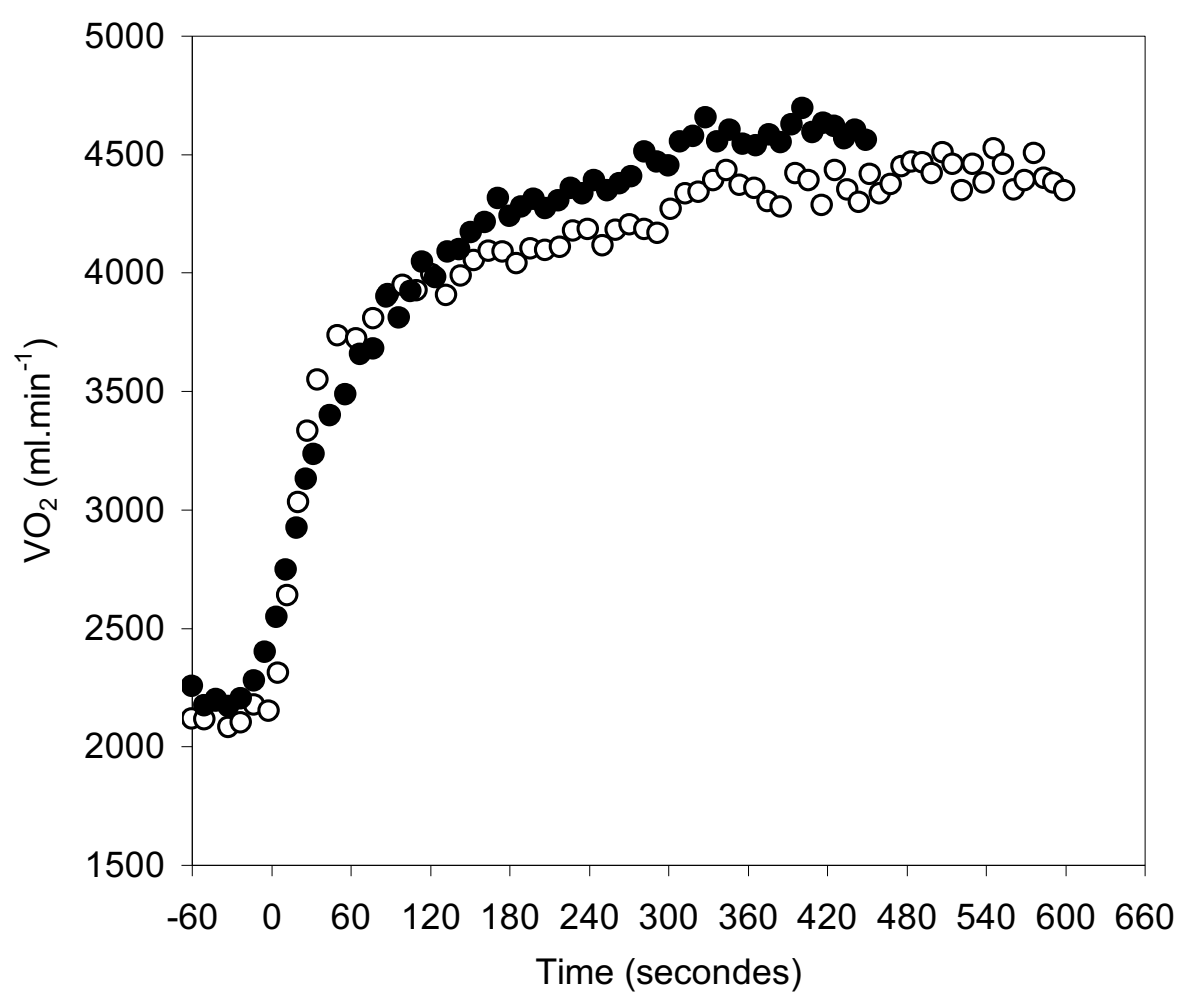

Figure 1. Example of oxygen uptake $\left(\dot{V} \mathrm{O}_{2}\right)$ response in 1 subject during a constant-power test 365 $(\mathrm{p} \Delta 50)$ at spontaneously chosen pedal rate $(\operatorname{SCPR}, \circ)$ and $+15 \% \operatorname{SCPR}(\bullet)$.

366 

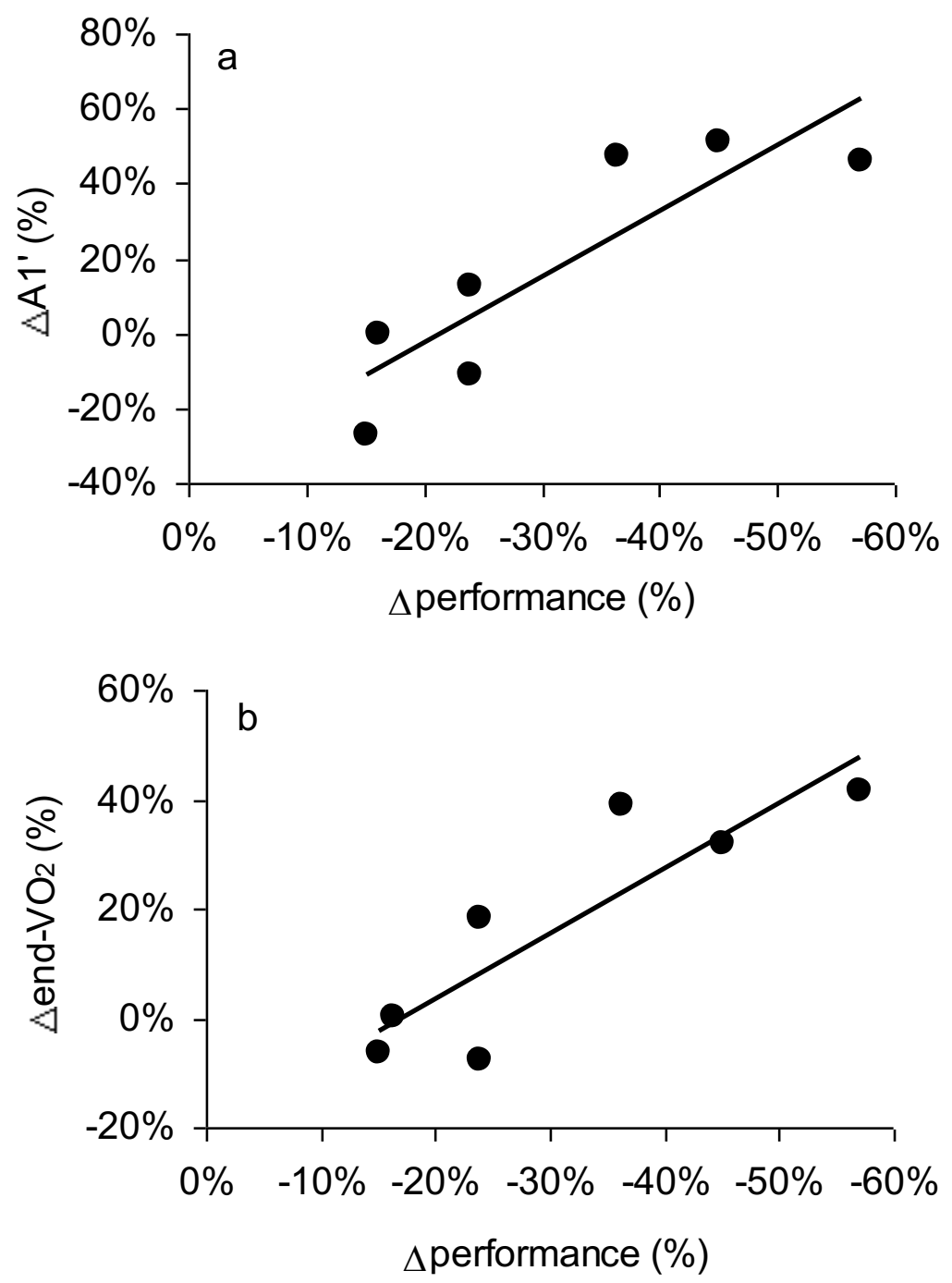

Figure 2. Relationship between the decrease of exhaustion time (i.e. $\Delta$ performance, $-31.1 \pm$ $37015.7 \%$ ) and a) the variation of amplitude of $\dot{V} O_{2}$ fast component (i.e. $\Delta \mathrm{A}_{1}, 17.0 \pm 29.6 \% ; \mathrm{r}=$ $371-0.87 ; \mathrm{P}<0.02) \mathrm{b}$ ) the variation of amplitude of the global $\dot{V} O_{2}$ response (i.e. $\Delta$ end- $\dot{V} O_{2}, 16.7$ $372 \pm 21.4 \% ; \mathrm{r}=-0.87 ; \mathrm{P}<0.02)$ computed between CPT cycled at $+15 \% \mathrm{SCPR}$ and at SCPR. 